\title{
AETIOPATHOLOGY AND CLINICAL PROFILE OF PATIENTS WITH HOARSENESS
}

\author{
Susan James ${ }^{1}$, Sunil S. Menon², K. Sasi Kumar³, Dilip Das 4 \\ ${ }^{1}$ Assistant Professor, Department of ENT, Government Medical College, Thiruvananthapuram. \\ ${ }^{2}$ Associate Professor, Department of Paediatric Surgery, Government Medical College, Thiruvananthapuram. \\ 3 Professor, Department of ENT, Government Medical College, Thiruvananthapuram. \\ ${ }^{4}$ Postgraduate Student, Department of ENT, TD Medical, Alaphuzza, Kerala.
}

\begin{abstract}
BACKGROUND

In India and other developing countries the prevailing lower economic status, poor nutrition, poor general health of the population, different food habits, vocal habits, smoking and drinking habits, unhealthy environment and different social customs definitely influence the incidence of hoarseness. As the aetiology of hoarseness is diverse and aetiological causes varies from country to country and centre to centre, the need for a study was felt to determine the aetiological distribution of the cause of hoarseness and the clinical profile of patients attending outpatient department of ENT, T. D. Medical College, Alappuzha.

The aim of this study is to study the various causes of hoarseness of voice; to study the associated clinical features; to study various treatment modalities and outcome.
\end{abstract}

\section{MATERIALS AND METHODS}

100 patients attending the Department of ENT Outpatient Department with hoarseness of voice were registered and their demographic details and symptoms and signs were recorded and analysed. The different aetiological and pathological features were analysed.

\section{RESULTS}

Malignant lesions were more common in patients who had a history of smoking. Of the total thirty eight cases (38) that had a history of smoking, 26 (68.42\%) developed malignancy; nineteen cases were diagnosed to have malignancy of larynx (19-50\%) and seven cases developed malignancy of Hypopharynx (07 - 18.42\%) and the remaining patients showed benign lesions (12 - 31.57\%). Of the total sixty two cases belonging to the non-smoking group, benign lesions were more common contributing 41 patients (35 - 56.45\%); 16 cases of the non-smoking group did not need a biopsy during the study period. Malignant lesions of the larynx and Hypopharynx were seen in eleven cases $(17.74 \%)$

\section{CONCLUSION}

Hoarseness usually affects older age groups. Males are more commonly affected than females. Manual labourers constitute the main occupational group of hoarse patients. Malignant lesions are more common in hoarse patients who have a history of smoking or alcoholism. Benign lesions are more common in patients with history of voice abuse.

\section{KEYWORDS}

Larynx, Hoarseness of Voice, Vocal Cords, Benign, Malignant and Laryngoscopy.

HOW TO CITE THIS ARTICLE: James S, Menon SS, Kumar KS, et al. Aetiopathology and clinical profile of patients with hoarseness. J. Evolution Med. Dent. Sci. 2017;6(19):1529-1533, DOI: 10.14260/Jemds/2017/336

\section{BACKGROUND \\ The voice is a natural medium well adapted to communicate emotional contact, whereas speech is a cultural medium that is suitable to convey intellectual contact. Speech is the main skill, which separates human beings from other animals. ${ }^{1}$ Hoarseness is a term used to describe change in voice quality and defined as a perceived rough, harsh or breathy quality to voice. The diseases causing hoarseness range from simple benign to the most malignant conditions. $^{2}$ Advent of microlaryngoscopy and endolaryngeal microsurgery as well as}

Financial or Other, Competing Interest: None.

Submission 28-01-2017, Peer Review 21-02-2017,

Acceptance 27-02-2017, Published 06-03-2017.

Corresponding Author:

Dr. Susan James,

Assistant Professor,

Department of ENT

Government Medical College,

Thiruvananthapuram.

E-mail: drsusanjames@gmail.com

DOI: $10.14260 /$ jemds $/ 2017 / 336$

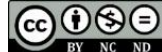

the recently introduced fibreoptic telescope have reduced our dependence on mirror examination and have greatly improved the diagnostic ability, especially in the cases of hoarseness. In India and other developing countries, the prevailing lower economic status, poor nutrition, poor general health of the population, different food habits, vocal habits, smoking and drinking habits, unhealthy environment and different social customs definitely influence the incidence of hoarseness. ${ }^{3}$ Though the common cause of hoarseness is benign lesion than malignant disease, opportunity for the cure has often been lost by delay under a benign diagnosis. ${ }^{4}$ Kleinsasser (1961) revolutionised the diagnosis and treatment of a laryngeal lesion using micolaryngoscopy. ${ }^{2}$ Killian in 1932 described the surgical and optical properties of stroboscopic light. In 1961, Van Laden described use of electronic stroboscope. ${ }^{5}$ In 1968, flexible fibreoptic laryngoscopy was introduced by Sawashima and Hirose. ${ }^{6}$ In the early 1970s, Jako Strong and Vaughan described coupling of $\mathrm{CO} 2$ laser to surgical microscope and this provided greater precision and facility for endolaryngeal surgery.7,8 As the aetiology of hoarseness is diverse and aetiological causes 
varies from country to country and centre to centre, the need for a study was felt to determine the aetiological distribution of the causes of hoarseness and the clinical profile of patients attending ENT outpatient department in T. D. Medical College, Alappuzha.

\section{Objectives}

To study the various causes of hoarseness of voice; to study the associated clinical features; to study various treatment modalities and outcome.

\section{MATERIALS AND METHODS \\ Study Setting}

This study was conducted in the Department of ENT, T. D. Medical College, Alappuzha.

\section{Study Duration}

The study was conducted during a period of one and a half years, starting from April 2010 to September 2012. Study design: The study was a prospective descriptive study.

\section{Study Population}

Patients attending ENT OPD with complaints of hoarseness were studied. A total of hundred patients were studied.

\section{Inclusion Criteria}

Patients more than twelve years of age complaining of hoarseness for more than three weeks' duration.

\section{Exclusion Criteria}

Patients not willing to be part of study; Patients with Congenital disorders like cleft lip and cleft palate; patients presenting with nasal, nasopharyngeal, oropharyngeal diseases; patients who are already under treatment of a speech therapist.

\section{Methods of Data Collection}

This is a descriptive study of 100 patients who came to ENT outpatient department with complaints of hoarseness, meeting the aforementioned criteria. A detailed and careful history was taken with reference to the onset, progression, duration, age, occupation, habits and associated symptoms. A detailed proforma for clinical examination was made. A detailed ENT examination including indirect laryngoscopy was done according to the proforma. Flexible laryngoscopy was done when there was difficulty in visualising larynx with a mirror. Routine blood investigations and TSH were done whenever necessary. Chest x-ray PA view and x-ray soft tissue neck lateral view were taken when required. CT scan of neck was taken when indicated. Direct laryngoscopy followed by biopsy or microlaryngoscopy biopsy was taken whenever suspicious looking areas were seen. Biopsy specimens were sent for histopathological examination and results were reviewed. CT scan of neck was taken when indicated. Further treatment was given according to biopsy results. Patients were sent for speech therapy when indicated.

\section{Analysis of Data}

The data collected from the study was analysed using SPSS software version 16

\section{RESULTS}

This is a descriptive study of 100 patients who came to the ENT outpatient department with complaints of hoarseness for more than three weeks' duration. Patients belonging to the seventh decade were the most common group affected with a total of 24 cases (24\%). Fifth and sixth decades were next most prevalent groups constituting 18 cases each (18\%). Younger age groups were less frequently affected with the least subjects coming from the second decade 6 cases $(6 \%)$ ), (Table 1). Patients with hoarseness were males with a $72 \%$ incidence and the male-to-female ratio was found to be $2.5: 1$.

\begin{tabular}{|c|c|c|}
\hline Age Group & Frequency & Percent \% \\
\hline $12-20$ Yrs. & 6 & 6.0 \\
\hline $21-30$ Yrs. & 11 & 11.0 \\
\hline $31-40$ Yrs. & 12 & 12.0 \\
\hline $41-50$ Yrs. & 18 & 18.0 \\
\hline $51-60$ Yrs. & 18 & 18.0 \\
\hline $61-70$ Yrs. & 24 & 24.0 \\
\hline $71-80$ Yrs. & 9 & 9.0 \\
\hline $81-90$ Yrs. & 2 & 2.0 \\
\hline Total & $\mathbf{1 0 0}$ & $\mathbf{1 0 0 . 0}$ \\
\hline Table 1. Showing the Age Distribution of Patients (n= 100)
\end{tabular}

Most of the patients in the study group were manual labourers (26). The next prominent group was constituted by the unemployed (17 cases). There was one singer in our study group. Housewives constituted (15) fifteen cases. Other jobs which normally do not use much voice including drivers, businessmen, etc. contributed fifteen cases (Table 2).

\begin{tabular}{|l|c|c|}
\hline & Frequency & Percent \\
\hline 1. Singer & 1 & 1.0 \\
\hline 2. Teacher & 7 & 7.0 \\
\hline 3. Hawker & 13 & 13.0 \\
\hline 4. Housewife & 15 & 15.0 \\
\hline 5. Manual Labourer & 26 & 26.0 \\
\hline 6. No Occupation & 17 & 17.0 \\
\hline 7. Others & 15 & 15.0 \\
\hline 8. Student & 6 & 6.0 \\
\hline Total & $\mathbf{1 0 0}$ & $\mathbf{1 0 0 . 0}$ \\
\hline
\end{tabular}

Table 2. Showing the Occupations of the Patients $(n=100)$

History of smoking was present in 38 cases. All 38 cases were males.

\begin{tabular}{|c|c|c|}
\hline & Frequency & Percent \\
\hline History of Smoking Present & 38 & 38.0 \\
\hline History of Smoking Absent & 62 & 62.0 \\
\hline Total & $\mathbf{1 0 0}$ & $\mathbf{1 0 0 . 0}$ \\
\hline \multicolumn{2}{|c|}{ Table 3. Showing Incidence of Smoking (n= 100) } \\
\hline
\end{tabular}

Malignant lesions were more common in patients who had a history of smoking. Of the total thirty-eight cases (38) that had a history of smoking, 26 (68.42\%) developed malignancy; nineteen cases were diagnosed to have malignancy of larynx (19 - 50\%) and seven cases developed malignancy of Hypopharynx $(07-18.42 \%)$ and the remaining patients showed benign lesions (12 - 31.57\%). Of the total sixty-two cases belonging to the non-smoking group, benign lesions were more common contributing 41 patients (35-56.45\%); 16 cases of the non-smoking group did not need a biopsy 
during the study period. Malignant lesions of the larynx and Hypopharynx were seen in eleven cases (17.74\%), (Table 4).

\begin{tabular}{|c|c|c|}
\hline Observations & Non-Smokers 62 & Smokers 38 \\
\hline Carcinoma of Larynx & $06-9.67 \%$ & $19-50 \%$ \\
\hline $\begin{array}{c}\text { Carcinoma of } \\
\text { Hypopharynx }\end{array}$ & $05-8.06 \%$ & $07-18.42 \%$ \\
\hline Benign Lesions of Larynx & $35-56.45 \%$ & $08-21.05 \%$ \\
\hline Non-Specific Laryngitis & $16-26.22 \%$ & $04-10.52 \%$ \\
\hline \multicolumn{3}{|c|}{ Table 4. Showing the Distribution of Laryngeal } \\
Lesions in Smokers and Non-Smokers (n = 100) \\
\hline
\end{tabular}

History of alcohol use was present in 38 cases (Table 5).

\begin{tabular}{|c|c|c|}
\hline & Frequency & Percent \\
\hline Valid History of Alcohol use Present & 38 & 38.0 \\
\hline History of Alcohol use Absent & 62 & 62.0 \\
\hline Total & 100 & 100.0 \\
\hline
\end{tabular}

There was a history of alcoholism in 38 of the 100 patients. Malignant lesions were more commonly seen in patients who had a history of alcoholism. There were 26 (68.42\%) patients among the 38 with history of alcoholism developed malignancy. Patients with benign lesions constituted 12 (31.87\%). Among the alcoholic patients, 19 developed malignant lesions of the Larynx (50\%) and 7 (18.42\%) developed hypopharyngeal carcinoma. Among the 62 nonalcoholic patients, 38 (62.29\%) showed benign lesions of the Larynx. Biopsy was not required in 16 cases of the nonalcoholic group and in 12 cases of alcoholic group; 16 (26.22\%) patients among the non-alcoholic group were presenting with non-specific laryngitis (Table 5).

\begin{tabular}{|c|c|c|}
\hline Observation & Alcoholics - 38 & Non-Alcoholics - 62 \\
\hline $\begin{array}{c}\text { Malignancy of } \\
\text { Larynx }\end{array}$ & $19-50 \%$ & $06-9.67 \%$ \\
\hline $\begin{array}{c}\text { Malignancy of } \\
\text { Hypopharynx }\end{array}$ & $07-18.42 \%$ & $05-8.06 \%$ \\
\hline $\begin{array}{c}\text { Benign Lesions of } \\
\text { Larynx }\end{array}$ & $08-21.05 \%$ & $35-56.45 \%$ \\
\hline $\begin{array}{c}\text { Non-Specific } \\
\text { Laryngitis }\end{array}$ & $04-10.52 \%$ & $16-26.22 \%$ \\
\hline $\begin{array}{c}\text { Table 6. Showing the Incidence of Laryngeal Lesions } \\
\text { among Alcoholic and Non-Alcoholic Groups (n = 100) }\end{array}$ \\
\hline
\end{tabular}

History of tobacco use (e.g. pan chewing, use of gutkha, etc.) was present in 16 cases (Table 6). Malignant lesions were seen in eleven cases out of the sixteen (68.75\%). Among the non-tobacco users, twenty-six cases developed malignancy (30.9\%). Majority of this group were having benign lesions (Thirty-nine cases) contributing $46.4 \%$.

\begin{tabular}{|c|c|c|}
\hline & Frequency & Percent \\
\hline History of Tobacco use Present & 16 & 16.0 \\
\hline History of Tobacco use Absent & 84 & 84.0 \\
\hline Total & 100 & 100.0 \\
\hline $\begin{array}{l}\text { Table 7. Showing the Inc } \\
\text { Disease in Patients using }\end{array}$ & $\begin{array}{l}\text { nce of Lar } \\
\text { bacco (n }\end{array}$ & \\
\hline
\end{tabular}

A positive history of voice abuse was present in 22 cases. Benign lesions were more common in voice abusers contributing to $16 / 22(72 \%)$. Of the twenty-two cases, 10 cases had vocal cord polyp and 5 patients had vocal cord nodule and 1 patient with vocal cord cyst (Table 7).

\begin{tabular}{|c|c|c|}
\hline Voice Abuse & Frequency & Percent \\
\hline Voice Abuse Present & 22 & 22.0 \\
\hline Voice Abuse Absent & 78 & 78.0 \\
\hline Total & 100 & 100.0 \\
\hline
\end{tabular}

A positive history of GERD was assessed based on the symptoms of the patients; history was present in 20 percent cases like heartburn, retching, frequent hawking and sudden spasm, etc. (Table 8).

\begin{tabular}{|c|c|c|}
\hline & Frequency & Percent \\
\hline History of GERD Present & 20 & 20.0 \\
\hline History of GERD Absent & 80 & 80.0 \\
\hline Total & $\mathbf{1 0 0}$ & $\mathbf{1 0 0 . 0}$ \\
\hline \multicolumn{2}{|c|}{ Table 9. Showing the Incidence of } \\
History of GERD (n= 100) \\
\hline
\end{tabular}

A positive history of pulmonary tuberculosis was present in one case. He had already taken 6 months ATT and was declared cured (Table 9).

\begin{tabular}{|c|c|c|}
\hline & Frequency & Percent \\
\hline History of Tuberculosis Present & 1 & 1.0 \\
\hline History of Tuberculosis Absent & 99 & 99.0 \\
\hline Total & $\mathbf{1 0 0}$ & $\mathbf{1 0 0 . 0}$ \\
\hline $\begin{array}{c}\text { Table 10. Showing the Incidence of } \\
\text { History of Tuberculosis (n= 100) }\end{array}$ \\
\hline
\end{tabular}

Cough was the most common associated clinical feature and was present in 29 cases (Table 10).

\begin{tabular}{|c|c|c|}
\hline & Frequency & Percent \\
\hline Cough Present & 29 & 29.0 \\
\hline Cough Absent & 71 & 71.0 \\
\hline Total & $\mathbf{1 0 0}$ & $\mathbf{1 0 0 . 0}$ \\
\hline \multicolumn{2}{|r|}{ Table 11. Showing the Incidence of } \\
Cough among the Patients $(\boldsymbol{n}=\mathbf{1 0 0})$ \\
\hline
\end{tabular}

Sore throat was the next most frequently associated symptom and was present in 16 cases (Table 11).

\begin{tabular}{|c|c|c|}
\hline & Frequency & Percent \\
\hline Sore Throat Present & 16 & 16.0 \\
\hline Sore Throat Absent & 84 & 84.0 \\
\hline Total & $\mathbf{1 0 0}$ & $\mathbf{1 0 0 . 0}$ \\
\hline \multicolumn{2}{|c|}{$\begin{array}{c}\text { Table 12. Showing the Incidence of Sore } \\
\text { Throat among the Patients (n= 100) }\end{array}$} \\
\hline
\end{tabular}

Nine patients presented with fever in the study (Table 12).

\begin{tabular}{|c|c|c|c|}
\hline & & Frequency & Percent \\
\hline Valid & Fever Present & 9 & 9.0 \\
\hline & Fever Absent & 91 & 91.0 \\
\hline & Total & 100 & 100.0 \\
\hline
\end{tabular}

A positive history of dysphagia was present in ten percent cases. Of the 10 cases, 8 patients were diagnosed to have malignancy of Hypopharynx and two patients had malignancy of Larynx (Table 13). 


\begin{tabular}{|c|c|c|}
\hline & Frequency & Percent \\
\hline Dysphagia Present & 10 & 10.0 \\
\hline Dysphagia Absent & 90 & 90.0 \\
\hline Total & 100 & 100.0 \\
\hline
\end{tabular}

Eight patients presented with neck node enlargement at the time of reporting to the OPD; 4 patients were diagnosed to have malignancy Larynx and the rest four had malignancy Hypopharynx (Table 14).

\begin{tabular}{|c|c|c|}
\hline & Frequency & Percent \\
\hline Neck Swelling Present & 8 & 8.0 \\
\hline Neck Swelling Absent & 92 & 92.0 \\
\hline Total & $\mathbf{1 0 0}$ & $\mathbf{1 0 0 . 0}$ \\
\hline Table 15. Showing the Incidence of Neck Swelling $(\boldsymbol{n}=\mathbf{1 0 0})$ \\
\hline
\end{tabular}

History of haemoptysis was present in three cases. All patients were diagnosed to have malignancy of larynx. Haemoptysis was present in ten percent cases of laryngeal malignancies (Table 15).

\begin{tabular}{|c|c|c|}
\hline & Frequency & Percent \\
\hline Haemoptysis Present & 3 & 3.0 \\
\hline Haemoptysis Absent & 97 & 97.0 \\
\hline Total & $\mathbf{1 0 0}$ & $\mathbf{1 0 0 . 0}$ \\
\hline Table 16. Showing the Incidence of Haemoptysis $(\mathbf{n}=\mathbf{1 0 0})$ \\
\hline
\end{tabular}

Associated noisy breathing was present in seven cases. All patients were having laryngeal malignancy. All patients who had stridor underwent tracheostomy during the study period (Table 16).

\begin{tabular}{|c|c|c|}
\hline & Frequency & Percent \\
\hline Stridor Present & 7 & 7.0 \\
\hline Stridor Absent & 93 & 93.0 \\
\hline Total & 100 & 100.0 \\
\hline \multicolumn{3}{|c|}{ Table 17. Showing the Incidence of Stridor $(n=100$} \\
\hline
\end{tabular}

Benign lesions of larynx (63) were more common than malignant lesions (37). Indirect Laryngoscopy finding of a proliferative lesion in the larynx was the most common finding. Vocal cord polyp was seen in 26 cases, which was the next most common single finding; 12 patients showed a congested vocal cord and fourteen cases showed a vocal cord nodule. Benign lesions altogether constituted 63 cases. Hypopharyngeal malignancy was seen in 12 cases. Histopathological finding of a malignant lesion of larynx was the most common single finding in the study (25 cases). Vocal cord polyp was the next constituting 26 cases (Table 17).

\begin{tabular}{|ll|c|c|}
\hline & Frequency & Percent \\
\hline 1. Normal & 1 & 1.0 \\
\hline 2. Congested Vocal Cord & 12 & 12.0 \\
\hline 3. Vocal Cord Polyp & 26 & 26.0 \\
\hline 4. Vocal Cord Nodule & 14 & 14.0 \\
\hline 5. Proliferative Lesion Larynx & 25 & 25.0 \\
\hline 6. & Proliferative Lesion & 12 & 12.0 \\
\hline Hypopharynx & 5 & 5.0 \\
\hline 7. Impaired Vocal Cord Mobility & 2 & 2.0 \\
\hline 8. Vocal Cord Keratosis & 3 & 3.0 \\
\hline 9. Vocal Cord Cyst & $\mathbf{1 0 0}$ & $\mathbf{1 0 0 . 0}$ \\
\hline \multicolumn{2}{|c|}{ Total } & Table 18. Showing the Incidence of Benign \\
\hline \multicolumn{2}{|c|}{ and Malignant Lesions of the Study (n= 100) } \\
\hline \multicolumn{2}{|c|}{} \\
\hline
\end{tabular}

The most common single modality of treatment used was microlaryngeal surgery, which was done in 35 cases. Outcome of treatment was measured subjectively at the end of treatment and more than half of the patients had a good result at the end of treatment; 52 cases reported that they got their original voice after treatment. In 21 cases, the quality of voice improved but they never attained the same quality as before. One patient reported a worsening of voice after treatment; 7 cases lost their normal voice, because of tracheostomy. In nineteen percent cases, there was no relief with treatment.

\begin{tabular}{|c|c|c|}
\hline & Frequency & Percent \\
\hline Relieved & 52 & 52.0 \\
\hline Improved & 21 & 21.0 \\
\hline No Change & 19 & 19.0 \\
\hline Worsened & 1 & 1.0 \\
\hline Tracheostomy & 7 & 7.0 \\
\hline Total & 100 & 100.0 \\
\hline \multicolumn{3}{|c|}{$\begin{array}{c}\text { Table 19. Showing the Treatment } \\
\text { Outcome among the Patients }(n=100)\end{array}$} \\
\hline
\end{tabular}

\section{DISCUSSION}

Hoarseness is obviously not a disease, but only the manifestation of a disease. The causes vary from self-limiting conditions like acute laryngitis to severe life-threatening malignancies. Benign conditions are more common than malignant lesions. Hoarseness lasting more than three weeks' duration obviously needs detailed evaluation and visualisation of larynx to rule out malignancy. Adults are more commonly affected with seventh decade being most commonly affected. In our study, the age of patients with hoarseness ranged from 13 - 82 yrs. (Mean 50.18 yrs.) and most patients (59\%) were in the group of $21-60$ yrs., which is considered as the most active period of life. Further patients in the 7lh decade (24\%) constituted the single largest group. Our observation is supported by Clark AR, ${ }^{9}$ Robert TS, ${ }^{10}$ Malzahn $\mathrm{K}^{11}$ and Shambu Baitha. ${ }^{12}$ Praveen $\mathrm{B}^{13}$ also reported the incidence in the age group of 20 - 50 yrs. to be $63.1 \%, 67.2 \%$ and $61.8 \%$ respectively. A male: female ratio of 2.57:1 was observed in this study. Other studies by Harmit M,14 Sumith $\mathrm{M}^{15}$ and Harold $\mathrm{P}^{16}$ also showed male predominance. As far as occupation is concerned, manual labourers constituted the single largest group of patients $(26 \%)$ in our study followed by jobless old age patients $(17 \%)$ and housewives comprising of 15 cases. The high incidence of hoarseness among labourers in our study may be explained by the fact that our hospital being rural based caters mostly to the village population comprising of farm labourers. Brock ${ }^{17}$ has mentioned that inhaled irritants, especially cigarette smoke as the most important predisposing factors for hoarseness. In the present study, a positive history of smoking was seen in 38 cases and alcoholism in 38 cases. Voice abuse was seen in 22 cases and a history of tobacco chewing in 16 cases; 20 cases had a positive history of GERD. In the study by Kameswaran $\mathrm{S}^{18}$ and Chakravarthy A, ${ }^{19}$ vocal abuses was noted in $72 \%$ of cases and in Kasim $\mathrm{B}^{20}$ study smoking was noted in $25.45 \%$ of cases, chewing tobacco preparation was noted in $17.27 \%$ and alcohol drinking in $12.72 \%$. James et $\mathrm{al}^{21}$ have found vocal abuse in $56 \%$. In this study, among males $64 \%$ were smokers and among females $38.24 \%$ had history of vocal abuse. The most common associated feature was cough followed by sore throat (16) and fever (9). Other associated features included 
difficulty in swallowing (10 cases) haemoptysis ( 3 cases) and neck swelling (8 cases). On indirect laryngoscopy examination (IDL) commonest finding was growth of vocal cords, consisting of 30 cases followed by vocal cord polyp which was seen in 27 cases. In the study by More PL, ${ }^{22}$ congestion of vocal cords was noted in $34.54 \%$ and growth in only $9 \%$ of cases on IDL examination. In our study, biopsy was done in 80 cases and histopathological finding most commonly encountered was squamous cell carcinoma in 28 cases. Next most common histopathological finding was a vocal cord polyp seen in 26 cases. Fifty-two cases reported that they got their original voice after treatment. In 21 cases the quality of voice improved, but they never attained the same quality as before. Seven cases lost their normal voice because of tracheostomy. In nineteen cases, there was no relief with treatment.

\section{CONCLUSION}

Hoarseness usually affects older age groups. Males are more commonly affected than females. Manual labourers constitute the main occupational group of hoarse patients. Malignant lesions are more common in hoarse patients who have a history of smoking or alcoholism. Benign lesions are more common in patients with history of voice abuse. Cough was the most common associated clinical feature. Associated neck swelling or a history of dysphagia or haemoptysis is seen more commonly in malignant cases. Indirect laryngoscopy findings usually correlate well with histopathological findings. Majority of patients with malignant lesions have a poor outcome.

Elderly patients with hoarseness should be examined carefully to rule out malignancy, especially when there is a history of smoking or alcoholism. Biopsy need to be taken in a hoarse patient, if suspicious lesions are seen on indirect laryngoscopy. Public should be made aware that voice abuse is a common cause of hoarseness.

\section{REFERENCES}

[1] Alan GK, John H. Scott browns otolaryngology. $6^{\text {th }}$ edn. Butterworth -Heinemann 1997:1-25.

[2] Cohen SM, Kim J, Roy N, et al. Prevalence and causes of dysphonia in a large treatment-seeking population. The Laryngoscope 2012;122(2):343-8.

[3] Nimish PP. Aetiological study of 100 cases of hoarseness of voice. Indian journal of otorhinolaryngology 1991;43(2):71-3.

[4] Chevalier J. Jackson diseases of ear nose and throat. $2^{\text {nd }}$ edn. WB Sounders Company 1959:p 576.

[5] Dimitrios A, George P, John L. Highlights in the evolution of diagnosis and treatment of laryngeal cancer. Laryngoscope 2003;113(3):557-62.

[6] Alfio F. Neoplasms of larynx. 1 ${ }^{\text {st }}$ edn. Churchill Livingstone 1999:369-400.
[7] Alfio F. Neoplasms of larynx. 1st edn. Churchill Livingstone 1999:1-26.

[8] Lakshmi V, Singh PP, Manish G. Efficacy of video laryngostroboscopy in management of hoarseness. Asian journal of ENT 2004;2(4):9-16.

[9] Clarke AR, Thomas M. Nomenclature of voice disorders and vocal pathology. Otolaryngologics clinis of north 2000;33(5):1035-45.

[10] Robert TS. Evaluation of professional singers. Otolaryngologic Clinics of North America 2000;33(5):923-56.

[11] Malzahn K, Dreyer T, Glanz H, et al. Autofluorescence endoscopy in the diagnosis of early laryngeal cancer and its precursor lesions. Laryngeoscope 2002;112(3):488-93.

[12] Baitha S, Raizada RM, Singh AKK, et al. Predisposing factors and aetiology of hoarseness of voice. Indian journal of Otolaryngology and Head and Neck Suregry 2004;56(3):186-90.

[13] Pravin B, Lamartine D, Mesquite AM, et al. Primary tuberculosis of larynx. Indian journal of Tuberculosis 1997;44(4):211-2.

[14] Harney M, Timan C, Donnehey M, et al. Laryngeal tuberculosis: an important diagnosis. The jounal of Laryngeology and Otology 2000;114(11):878-80.

[15] Sumit M, Arunava S, Joydeep C. Laryngeal tuberculosis in MDR-TB presenting as laryngeal carcinoma. Indian journal of Otolaryngeology 2001;53(4):321-2.

[16] Brass LS, White JA. Granulomatous diseases of the larynx. J La State Med Soc 1991;143(1):11-4.

[17] Broek P. Acute and chromc laryngms. In: Scott brown's otolaryngology. $6^{\text {th }}$ edn. Hlbbert J (edr). Oxford, Butterworth Hememann 19975;5:1-20.

[18] Kameswaran S, Mohan K. ENT disorders in a tropical environment. 1 ${ }^{\text {st }}$ edn. MERF publications 1979:39-45.

[19] Chakaravarti A, Shashidhar TB, Sahni JK. Primary amylodosis of larynx. Asian journal of ENT 2005;3(1):13-5.

[20] Kasim BA, Ali AB, Anitha B, et al. Laser in Treatment of laryngeal amyloidosis: a case report. Indian journal of Otolaryngeology 2001;53(2):152-4.

[21] James AK, Allen JB. The etiology and pathogenesis of laryngeal carcinoma. Otolaryngological clinics of North America 1997;30(1):1-19.

[22] More PL, Kim D, Selby G, et al. Detection of laryngeal carcinoma and epithelial hyperplastic laryngeal lesions via rapid-access dysphonia clinic. The journal of Laryngology and Otology 2004;118(8):633-6. 